\title{
SOBRE OS DIREITOS HUMANOS E SUA TUTELA
}

\author{
Alysson Leandro Mascaro \\ Doutorando em Filosofia do Direito na Faculdade de \\ Direito da Universidade de São Paulo
}

\begin{abstract}
Resumo:
Os direitos humanos, a mais importante das etapas de sua construção jurídica, a popularização da questão dos direitos humanos, a vulgarização deste tema que representa uma vitória e ao mesmo tempo um grande problema. Uma releitura dos direitos humanos mesclada com os caminhos da Filosofia são os propósitos minuciosos do autor.
\end{abstract}

\begin{abstract}
:
The human rights, the most important stage of their juridical construction, the popularization of human rights' question, the vulgarization of this theme that represents a victory and in the same time a big problem. A human rights' rereading mixed with the Phylosophy's ways are the minutes purposes of the author.
\end{abstract}

Unitermos: crítica aos direitos humanos; tutela jurídica efetiva; transformação social.

Que o capítulo dos direitos humanos represente uma das mais importantes etapas de nossa construção jurídica, está a abundante literatura, muito dela bastante abalizada, a nos demonstrar. Parece vencido, ao menos academicamente, o preconceito dos juristas contra o tema dos direitos humanos. O que não quer dizer, muito pelo contrário, que sejam os direitos humanos, em sua vivência, uma realidade já concretizada e plenificada.

Da mesma forma que nas últimas décadas aumenta a popularização da questão dos direitos humanos, aumenta também uma certa incompreensão a respeito do tema que só é cada vez mais reforçada quanto mais vulgarmente banalizada é a idéia. Corre com os direitos humanos o mesmo que um dia aconteceu com temas como democracia ou ideologia. Todos "sabemos" intuitivamente o que sejam, até mesmo sabemos tomar posições e decisões a respeito destas questões, mas destes temas não conseguimos esboçar conceitos nem definições melhores quando chamados a dá-los; mantemos ainda pés de barros enquanto as mãos já estão operando e as cabeças sentenciando contra e a favor. O que é democracia, o que é ideologia, o que são direitos humanos, todas estas parecem perguntas sem muita necessidade na nossa realidade contemporânea porque todos parecem que saber a resposta. Mas justamente quando o conceito é utilizado por todos - e já não se sabe mais para que fim nem tampouco para que o interesse na recorrência ao tema - é que é preciso saber distinguir joios e trigos, voltando-se à base mesma de compreensão do conceito. 
Não escapam os direitos humanos desta vulgarização que os põem na boca de todos e, ao mesmo tempo, para dizer nas conhecidas palavras de Heidegger, de ninguém. Todo mundo e ninguém parecem ser muito próximos. Não é outra a razão de logo vermos, pela boca comum, infelizes expressões como "direitos humanos de bandidos" "direitos humanos da vítima" ou, então, concepções aparentemente definitivas, como direitos humanos como sinônimos de direitos naturais, ou direitos humanos constitucionais etc. A vulgarização do tema dos direitos humanos, ao mesmo tempo que representa uma vitória, representa um grave problema. Por detrás dos usos do conceito podem estar posições as mais avessas e contrárias aos direitos humanos, bem como por democratas se declarou, consciente ou inconscientemente, boa parte dos ditadores do século XX. Da mesma forma que foi preciso perguntar a estes ditadores o que entendiam por democracia, para salvar a própria, é preciso também nos dias atuais perguntarmo-nos a respeito dos direitos humanos, querendo salvá-los.

Esta é uma necessidade imperiosa a favor dos direitos humanos, necessidade que é no fundo tão velha quanto a busca da verdade, tão velha quanto o patrono da Filosofia, Sócrates, querendo iluminar os conceitos na velha Atenas, que tanto se reputava democrática, mas que era uma polis escravista e sectária também. Esta imperiosidade da destruição de nossas verdades aparentemente óbvias e das quais nunca nos indagamos é o primeiro passo para uma verdadeira aproximação da questão dos direitos humanos. Quando antigos áulicos de ditaduras, impiedosos e frios tecnocratas, banqueiros internacionais e organismos financeiros exploratórios parecem todos estar de acordo "a favor" dos direitos humanos, perguntemo-nos sobre o que se entende por isso.

Num rico prefácio da obra Fenomenologia Existencial do Direito, de Jeannette Antonios Maman, Aloysio Ferraz Pereira encaminha algumas possiveis correntes contemporâneas de compreensão do Direito, que compreendem também, por seu turno, certas concepções sobre os direitos humanos. As decorrências destas visões são as várias abordagens e os vários conceitos e utilizações do termo direitos humanos na atualidade jurídica e jusfilosófica. Diz o antigo professor da Universidade de São Paulo:

“(...) Pois, com efeito, esses lugares comuns, de origem politico-jurídica, não filosófica, embora confluentes no final, parecem-me redutiveis a três. Resumindo:

1. o do individualismo voluntarista, que hoje alimenta a ideologia internacionalista e os negócios da globalização;

2. o da retórica lingüistico-sofistica, a serviço também do capital mundializado e do correspondente consumismo periférico; $e$

3. o do tecnocientificismo conceitual, alheio a toda filosofia, mas temente a Deus, com laivos involuntários de jusnaturalismo (leia-se jusracionalismo de tipo utilitário)."

1. PEREIRA, Aloysio Fcrraz, Prefácio à obra de MAMan, Jcannette Antonios, Fenomenologia Existencial do Direito, São Paulo, Edipro, 2000, p. 14. 
Os caminhos da Filosofia do Direito, no sentido de desvendar as questões atinentes à questão dos direitos humanos, devem desde logo se emancipar das infelizes tradições que ainda confinam o Direito ora ao tecnicismo, ora a um racionalismo capitalista, ora à manutenção da "ordem" como se fosse isto algo inexorável e amplamente conhecido, e também deve a Filosofia do Direito, buscando construir mais altos conceitos de direitos humanos, escapar do sociologismo da rama que com alguns bordões sobre globalização faz silogismos fáceis sobre as derivações e as possibilidades dos direitos humanos na realidade, utilizando como conceito de direitos humanos este mesmo mal-esclarecido pelo conservador arremedo da filosofia jurídica tradicional.

As vogas dos direitos humanos.

Na perspectiva do professor Aloysio Ferraz Pereira, um primeiro caminho das trilhas dos direitos humanos na atualidade é a do individualismo voluntarista. Este individualismo voluntarista é a típica construção moderna dos direitos humanos. É, talvez, a mais insistente concepção que brota nos juristas da atualidade, com uma proposta muito clara: a alimentação de uma lógica econômica globalizada.

Esta concepção moderna, liberal, alimentou grande parte da formulação jurídica dos séculos XVIII e XIX, esteve bastante desprestigiada na maior parte do século $\mathrm{XX}$, mas parece ter voltado à tona nos últimos tempos como teoria válida e útil num mundo internacionalizado e globalizado, neoliberal na expressão que quer encerrar esta definição.

Estes direitos humanos voluntaristas podem ser medidos pelas ações internacionais visando à defesa de minorias, ao combate à violência ou à defesa da democracia, tudo isto por meio de países como os EUA, cujo impulso para ditar os direitos humanos aos países periféricos é a máscara que esconde seus objetivos mais canhestros, negociais e exploratórios no plano mundial. É de se perceber, aliás, que boa parte das guerras financiadas e mantidas pelos EUA e outros países dominantes tem discurso motivador na violação de direitos humanos. A lógica destas ações, no entanto, passam longe do problema.

A segunda via da construção destes direitos humanos são a sua utilização retórica, sofistica, que faz com que direitos humanos sejam, na atualidade, objeto de adorno de teses acadêmicas, cereja de bolo de eventos jurídicos e de cidadania, insuflando inclusive abertura de cátedras em universidades para o tema. É arroz de festa, da mesma forma que os jantares das grandes damas da sociedade a favor dos pobres. A vertente mais sofisticada e filosófica desta via é a sua formulação pela filosofia da linguagem, que a torna um problema hermenêutico esvaziado de sociabilidade, historicidade e senso critico, portanto apto a não produzir efeitos radicais na prática, mantendo então a ordem no modo pelo qual ela já está efetivada.

A terceira via apontada por Ferraz Pereira, esta sim é muito mais próxima da realidade jurídica atual, a do tecno-cientificismo conceitual misturado com pretensões a direito natural. Os direitos humanos passam a ser, nesta perspectiva, conceito, 
ferramental, instrumento, cuja validade está na sua própria concepção formal, valem porque estão expressos no Direito, e portanto ao jurista cabe apenas aplicá-los como se aplicam quaisquer outros instrumentais legais.

Se não são utilizados tecnicamente, tendo por base o próprio dogmatismo, são utilizados então tendo por base laivos jusnaturais. O perigo aqui aumenta ainda mais. O jurista que se utiliza dos direitos humanos porque são lei não faz mais nada, a não ser respaldar a legitimação do sistema que confina o Direito às leis inefetivas. $O$ jurista que se utiliza dos direitos humanos porque pensa que estes são lei natural - e jusnaturalismo aqui tomado não na sua acepção grega, mas na medieval ou moderna, ou seja, como lei, vinda de Deus ou da razão individual - escapa do tecnicismo, mas cai na metafísica. Vale dizer, em todos estes casos, a crítica verdadeira ao desrespeito aos direitos humanos não é feita. No primeiro caso porque estes atos individuais multinacionais são paliativos a bem dos negócios da globalização. No segundo caso porque são falsos e acríticos. No terceiro caso porque são ou dogmáticos - e o dogmatismo pode ser tanto hoje a favor dos direitos humanos quanto pode ser contra amanhã - ou então são metafísicos e não enxergam um palmo do problema social da questão.

Trazer a compreensão dos direitos humanos para a História Social do homem, para as estruturas sociais de exploração e os conflitos de classe, trazer a crítica para um patamar suficiente que a faça ser compreendida a partir de suas causas mais profundas, tratando da questão radicalmente e não com paliativos, isto em geral não vem sendo feito pelas teorias jurídicas a respeito dos direitos humanos.

O pensar crítico sobre os direitos humanos.

Marx, na Questão Judaica, pela primeira vez expôs uma crítica filosófica profunda aos direitos humanos tomados na lógica legalista liberal. A contundência marxista se faz pela via da exposição da limitação e da parcialidade dos direitos humanos, tomados pela ótica formal, individual e liberal. Diz Marx:

"Os droits de l'homme, os direitos humanos, distinguem-se, como tais, dos droits du citoyen, dos direitos civis. Qual o homme que aqui se distingue do citoyen? Simplesmente, o membro da sociedade burguesa. Por que se chama membro da sociedade burguesa de "homem" homem por antonomásia, e dá-se a seus direitos o nome de direitos humanos? Como explicar o fato? Pelas relações entre o Estado político e a sociedade burguesa, pela essência da emancipação política.

Registremos, antes de mais nada, o fato de que os chamados direitos humanos, os droits de l'homme, ao contrário dos droits du citoyen, nada mais são do que direitos do membro da sociedade burguesa, isto é, do homem egoista, do homem separado do homem e da comunidade. "2 
Na Sagrada Família, continua Marx num balanço dos direitos humanos:

"Já se demonstrou como o reconhecimento dos direitos humanos pelo Estado moderno tem o mesmo sentido que o reconhecimento da escravidão pelo Estado antigo. Com efeito, assim como o Estado antigo tinha por fundamento natural a escravidão, o Estado moderno tem como base natural a sociedade burguesa e o homem da sociedade burguesa, isto é, o homem independente, ligado ao homem somente pelo vínculo do interesse particular e da necessidade natural inconsciente, tanto a própria como a alheia. O Estado moderno reconhece esta sua base natural, enquanto tal, nos direitos gerais do homem. Todavia, ele não é seu criador. Sendo como é, produto da sociedade burguesa, impelida por seu próprio desenvolvimento além dos velhos vínculos politicos, ele mesmo reconhece, por sua vez, seu lugar de nascimento e sua própria base mediante a proclamação dos direitos humanos. ${ }^{13}$

A crítica marxista aos direitos humanos, tomados nesta sua acepção liberal, não é oposição ou negação dos direitos humanos. Pelo contrário, é a afirmação da parcialidade de sua feição liberal, vale dizer, é a afirmação da impossibilidade concreta de direitos humanos, tomados numa feição plena, substancial, se fincada numa perspectiva liberal. Esta perspectiva só faz por afirmar a proclamação dos direitos humanos. ${ }^{4}$ Não se confunde, pois, esta postura, de dialética de classes dos direitos humanos, com uma eventual crítica do passadismo, dos movimentos absolutistas ou pré-liberais, que construíram uma crítica aos direitos burgueses por razão da manutenção de seus privilégios. A crítica marxista é a crítica do avanço para dentro do problema, e não para fora, de retorno ou conservação dos privilégios. ${ }^{5}$

\section{Op. Cit., p. 75 .}

4. O filósofo do Dircito Villey trata da questão numa de suas últimas obras: "J'estime donc fondée la critique de Marx; elle portait, dans La question juive, contre les formules de la Déclaration de 1789, qui sont un écho de la doctrine de Locke. Ces droits de l'homme "formles" (libertés) ne sont pas pour tous, mais pour quelques-tuns. Ils servirent à la destruction de la monarchie, mais lui substituèrent une oligarquie. Ils ont signifié la domination politique de la classe bourgeoise; dans l'économie, du capitalisme" VILLEY, Michel. Le Droit et les Droits de L'Homme. Paris, PUF, 1998, p. 152.

5. Diferente, pois, de críticas que seguem pelo caminho do conservadorismo ou do reacionarismo, como parece ser o caso cxemplar de Edmund Burkc. Suas posições, no que dizem respeito aos direitos humanos, são muito nítidas, numa crítica quc $\mathrm{cm}$ nada Icmbrará a postcrior crítica marxista: “(O homem) abdica de todo direito de ser seu próprio govermante. Inclusive, numa grande medida, ele abandona o direito de autodefesa, a primeira lei da natureza. Os homenss não podem desfiutar dos direitos de um Estado civil e incivil ao mesmo tempo. (...) A fim de que possa garantir uma parte da liberdade, ele faz uma concessão como caução à sua totalidade. (...) De que vale discutir um direito humano abstrato à comidla e au medicamento? A questão está no método de produzi-los e administrá-los. Nesta deliberaçào, sempre aconselho a buscar a ajuda do agricultor e do médlico, em lugar da do professor ou da metafisica ". In Os Clássicos da Politica, Vol. 2, São Paulo, Ática, 1995, p. 38. 
A insistência da crítica marxista é a de demonstração da parcialidade do sentido formal dos direitos humanos. $\mathrm{Na}$ verdade, a tomada de posição a favor dos direitos humanos, na perspectiva marxista, é uma ação que chega ao cerne do problema da exploração, do domínio dos meios de produção, e, pois, envolve muito mais que a mera declaração de direitos. Envolve, sim, o que não faz dos direitos humanos sinônimo de direitos do homem burguês: a transformação das relações sociais, portanto muito mais um problema da práxis do que propriamente da teoria.

O problema da liberdade real e não da formal, da igualdade real e não da isonomia, do exercício pleno dos direitos humanos, só tem resolução, na perspectiva marxista, pela práxis e não pela declaração de direitos. Aliás, pode-se mesmo apontar que os direitos sociais, que são os que vêm em geração seguinte aos direitos humanos formais (de primeira geração), são sempre direitos de concretude relacional, de práxis muito mais do que de forma. Por isso são tão mais próprios do campo da atividade política do que os direitos burgueses, mais próprios do campo da atividade judiciária.

Qual o sentido deste avanço crítico de Marx no tratamento da questão dos direitos humanos? Talvez seja o de inscrever os direitos humanos não numa essência genérica humana, tampouco numa espécie de dignidade indevassável da individualidade. A grande contribuição marxista à questão dos direitos humanos talvez seja a inserção definitiva do problema no aspecto social do homem, na sua relação social e produtiva, na sua práxis enfim. Tomados na acepção liberal, os direitos humanos são problema de simples afirmação jurídica. No mundo do Direito e da tutela jurídica esgotam-se suas possibilidades e sua efetividade. Tomados num sentido crítico profundo, os direitos humanos demonstrar-se-ão os direitos da práxis humana, uma construção relacional, social, cuja efetividade não se perfaz apenas pelo campo do Direito, mas, muito mais, está ligado ao problema da efetivação dos excluídos e da transformação das relações de exploração social. Este prisma talvez tenha inspirado muito das lutas que, a partir do século XIX, insurgem-se contra o Direito dado pela apenas pela forma para a busca de consecução do Direito afirmado pela História Social do homem. Aliás, todas as gerações posteriores de direitos humanos que vão se sucedendo aos primeiros, individuais e formais, não são mais gerações de direitos meramente declarados, mas direitos que demandam relações sociais, políticas e econômicas de efetivação.

A crítica social na inefetividade formal.

A crítica que aprofunde o problema dos direitos humanos de maneira dialética não quer jamais dizer respeito a um certo abandono de ganhos históricos liberais. A dialética marxista sempre pressupõe, na verdade, a tensão entre pólos cuja afirmação é concreta, e não puramente teórica. Vale dizer, é impossível uma dialética de superação do legalismo liberal dos direitos humanos sem que já se tenha por dado esta instância dialética. Da mesma forma como a dialética marxista esteve despreparada para pensar o problema da passagem direta do feudalismo ao socialismo - posto que a perspectiva da transformação dialética socialista tem por base a tese capitalista -, 
também é muito dificil pensarmos um aprofundamento crítico da questão dos direitos humanos sem ter por base o seu dado liberal formal. O caso brasileiro, no entanto, é uma fuga do modelo clássico de direitos humanos liberais. A crítica marxista ao direito liberal talvez não encontre um modelo liberal típico no exemplo brasileiro. Na verdade, ainda persiste, até a atualidade, uma relação da sociedade brasileira para com os direitos humanos, cujo esteio talvez seja pré-liberal, ou paraliberal pelo menos.

Marilena Chauí aponta este dilema do caso brasileiro, que não chegou aos direitos humanos liberais e portanto deverá ter uma crítica muito peculiar ao modelo liberal:

"O Brasil é uma sociedade autoritária, na medida em que não consegue, até o limiar do século XXI, concretizar sequer os principios (velhos de três séculos) do liberalismo e do republicanismo. Indistinção entre o público e o privado, incapacidade para tolerar o princípio formal $e$ abstrato da igualdade perante a lei, combate da classe dominante às idéias gerais contidas na Declaração dos Direitos do Homem e do Cidadão, repressão às formas de luta e de organização sociais e populares, discriminação racial, sexual e de classe, a sociedade brasileira, sob a aparência de fluidez (pois as categorias sociológicas, válidas para a descrição das sociedades européias e norte-americana, não parecem alcançar a realidade brasileira), estrutura-se de modo fortemente hierárquico, e, nela, não só o Estado aparece como fundador do próprio social, mas as relações sociais se efetuam sob a forma da tutela e do favor (jamais do direito) e a legalidade se constitui como círculo fatal do arbitrio (dos dominantes) à transgressão (dos dominados) $e$, desta, ao arbitrio (dos dominantes)."'

A dificuldade de uma crítica socialista ao modelo liberal dos direitos humanos é que, numa realidade como a brasileira, sequer contamos com estes. A história de nossas ditaduras (a última acabada há menos de vinte anos), uma história de formação social que se forjou na escravidão e na exploração mais vil possivel, a mentalidade autoritária em cadeia, do primeiro ao último numa perversa relação de domínio sem respeito, tudo isso faz com que os direitos humanos, tomados na sua lógica liberal, já sejam considerável avanço perante a sua negação sistemática que impera até a atualidade. No entanto, é preciso ainda afirmar a crítica mais profunda, que na verdade é a crítica ao próprio sistema social de estruturação da opressão, de tal modo que os direitos humanos, no caso brasileiro, não venham a ser reparo dos desrespeitos, mas a própria estrutura social de dignidade e respeito. Ainda hoje, no Brasil e nos países explorados, já se tem que vencer a fronteira do caráter social dos direitos humanos sem mesmo ter chegado à fronteira dos direitos humanos liberais individuais. A batalha pelos direitos humanos em nossa realidade brasileira, pois, é sempre dupla.

6. CHAUİ, Marilena. Conformismo e Resistência. São Paulo, Brasiliensc, 1993, p. 47. 
A crítica vencida e as garantias das possibilidades neoliberais.

A postura de afirmação crítica dos direitos humanos vem sucumbindo, nos últimos tempos, a uma lógica devastadora, que de direitos lhumanos só tem uma pálida máscara, mas cujo conteúdo é seu exato contrário, na medida em que esfacela as conquistas sociais. Se desde o século XIX a luta pelos direitos humanos aprofundou-se pelo ângulo da sua afirmação plena, histórica, social, a partir das classes exploradas e oprimidas, o que se vê na realidade atual, no entanto, são os direitos humanos não como luta, não como afirmação da dignidade dos explorados, mas sim como garantias genéricas dos exploradores. A luta social e as tensões que fizeram dos direitos humanos objeto de concreção social foram abandonadas para a afirmação de uma espécie de direitos humanos meramente formalista, aos moldes do típico liberalismo jurídico de antanho. $\mathrm{O}$ desmonte da preocupação social e das lutas de classe fizeram com que $o$ problema dos direitos humanos seja, mais uma vez, um mero problema de forma.

O claro resultado de um mundo que vai entrando numa organização capitalista neoliberal é a expansão das garantias capitalistas formais para dentro de todas as nações, esfacelando as lutas sociais locais e homogeneizando os mínimos direitos formais que interessam ao capitalismo. Se lembrarmos que o projeto liberal, iluminista e burguês do século XVIII era a lei universal, pode-se perceber que este projeto venceu, mais de dois séculos depois.

Kant, na Paz Perpétua, pontificava a respeito de uma legislação cosmopolita, cujas estipulações fossem universais. Baseava-se nos imperativos categóricos e num pano de fundo ainda mais amplo que era o da pressuposição de interesses e necessidades iguais para todos os seres humanos. Ora, os únicos interesses universalizáveis são os da classe burguesa, a única que se afirma como classe universal. $\mathrm{O}$ antigo regime, ao qual se opõe a burguesia, é regime de status, de privilégio; portanto, não é universal. A crítica contemporânea, por seu turno, insiste no conflito social, no conflito de classes, portanto não em um direito para todos, mas um direito de classes. Somente o típico pensamento burguês moderno contenta-se com os remédios jurídicos genéricos, posto que é exatamente na forma universal que se afirmam os interesses burgueses. Liberdade, sendo liberdade formal e negocial, universal portanto, é a liberdade burguesa. Igualdade, sendo a igualdade formal e não a concreta, a de possibilidades, é a liberdade burguesa, que não a diferencia da nobreza e portanto não lhe aferroa com privilégios alheios, e nem tampouco diferencia os excluídos do poder econômico da classe burguesa. Os direitos humanos, esvaziados da sua perspectiva concreta, social, de classe, esvaziados dos interesses sociais que estão em conflito estrutural na șociedade capitalista, não são nada mais que os direitos burgueses.

Os tempos atuais, tempos neoliberais e de exacerbação da exploração capitalista em nível mundial, são tempos que insistem novamente no discurso dos direitos humanos, no discurso universalista destes direitos. Esvaziam-se os direitos humanos sociais, toleram-se os direitos de terceira ou quarta geração até o ponto em que estes não afetem o capitalismo mundial (os EUA, arautos dos direitos humanos, 
não aceitam as restrições ambientais em seu próprio território, só no dos outros). No entanto, a afirmação maior da atualidade é a dos direitos individuais, dos direitos que são mínimos fundamentais à classe burguesa, agora sim definitivamente uma classe universal, posto que o capitalismo está vivo em todas as partes do mundo. Esta é a vitória dos direitos humanos: a vitória do capitalismo, da lógica burguesa, da impossibilidade de afirmação dos direitos sociais e da luta social do homem. São os direitos possíveis e necessários ao sistema capitalista. Se eles se consideram o supra-sumo das preocupações mais altas do homem, todo o resto só haverá por muito generoso acréscimo, e generosidade não está mais na conta de preocupação dos que tratam do tema.

Esta vitória dos direitos humanos liberais, burgueses em essência, é a vitória do capitalismo. Como este vence em plano mundial, vencem também em plano mundial estes direitos humanos. Daí entender-se que a única superpotência mundial mede seus interesses comerciais pela tábua dos direitos humanos. A tábua e a medida confluem.

Estes direitos humanos hoje em voga são o mínimo necessário para o exercício capitalista universal. Respeito universal à propriedade e ao contrato, respeito à liberdade formal e a igualdade formal, democracia formal que afaste rupturas, são as essências que se difundem como faróis desta nova era. As garantias mínimas das possibilidades burguesas parecem ser nada diferente do que um velho clássico do pensamento burguês liberal, Jhering, já asseverava nos idos do século XIX. A Luta Pelo Direito é a lógica de que o único direito universal é o mínimo burguês para a "luta" e o demais - dentro dele os direitos sociais e as conquistas sociais - não deve ser objeto do Estado, da Política e do Direito, mas objeto de luta individual ${ }^{7}$. As críticas atrozes a esta impiedosa luta de burgueses e proletários, entre classes sociais com poderes tão distintos jogadas todas à mesma arena, parecem não ter bastado. $O$ mundo retorna à prática e ao pensamento liberal, e o direito como mínimo de garantia das possibilidades burguesas, que era o direito de Jhering e dos burgueses do passado, é novamente reabilitado, agora com um rótulo repintado - com néons e cartazes atraentes de coca-colas e mcdonalds -, ao qual se deu o nome de direitos humanos.

A crítica parece definitivamente vencida. A afirmação de uma luta de classes, de uma luta dos oprimidos, dos sem-terra, sem-teto, sem-possibilidades, já não vai mais comovendo os corações e os intelectos que só se sensibilizam pelas promoções das grandes cadeias de lojas que destinam uma certa porcentagem dos lucros de um dia do ano para causas beneméritas de caridade. Voltam a ser os direitos humanos direitos formais, universais e burgueses, volta o problema social a ser problema de segurança pública e de polícia, e volta a ser a resolução do problema social problema de benemerência de damas da sociedade ou de empresas preocupadas com o futuro das

7. "O direito privado, e não o direito piblico é a verdadeira escola de edućação politica dos povos: se alguém quiser saber como zum povo defenderá, se for preciso, os seus direitos politicos e sua politica internacional, bastará examinar a forma por que o simples particular defende os direitos próprios da vida privada". JHERING, Rudolf von. A Luta Pelo Direito. Rio de Janciro, Forense, 1994, p. 63. 
criancinhas do mundo. Neste mundo só há espaço para quem seja amigo dos direitos humanos, mas não há espaço para os verdadeiros direitos humanos.

Sobre a tutela dos direitos humanos.

No entanto, é preciso que se reponha e que se compreenda a dialética do problema dos direitos humanos. Principalmente se tivermos em vista o ângulo dos povos explorados, como é o caso do povo brasileiro. Os direitos humanos vistos pela ótica dos interessados maiores na globalização, na liberalização de mercados, levam a esta concepção burguesa, formal, insuficiente. É preciso analisar a questão pelo lado dos explorados, dos excluídos. Da perspectiva destes, o problema é outro, e sabor da vitória tem muitas vezes paladar de derrota.

Ainda na atualidade a luta pelos direitos humanos talvez seja das mais dignas aos povos, às nações e aos indivíduos. No Brasil, ainda hoje não vencemos o patamar da afirmação liberal dos direitos humanos. Não chegamos ao ponto de poder dizer consolidado o mundo formal que tanto interessaria à burguesia, na qual todo indivíduo é respeitado em seus direitos fundamentais. Não chegamos ao mínimo.

No caso brasileiro, vê-se muito nitidamente o quanto falta para que se consolide uma experiência histórica de respeito aos direitos humanos. A estrutura social, os aparatos de repressão, os detentores dos meios de comunicação, são todos violadores contumazes dos direitos humanos mínimos liberais. Na verdade, são violadores de todos os direitos humanos, inidividuais, liberais, políticos, de cidadania formal, e também dos sociais, de classe, de conscientização e de participação social ativa, de cidadania ativa. Não temos nada a comemorar neste sentido. Aliás, as atuações do Governo federal atual nem chegam ao ponto de defender direitos humanos liberais, mas simplesmente de fazer proselitismo e falsidades hipócritas a respeito do tema.

A dialética dos direitos humanos, que supera os direitos formais para uma definitiva libertação do homem pela práxis, pela sua emancipação social e econômica, na qual não haja o direito do homem burguês, mas a satisfação do homem pleno, esta dialética talvez seja o imperativo fundamental ao qual se impõe que nos atentemos e lutemos, mas, no entanto, a realidade brasileira, em muitos aspectos, sequer chegou à instância dos direitos humanos formais. Por isso se têm, aí, duas lutas fundamentais.

A primeira, a luta incessante para que não haja, no povo brasileiro, o estado de desrespeito (que hoje é atroz) dos direitos humanos, estado este que é típico de um povo cuja lei é comprada e usada a gosto pelas elites, que não são sequer elites liberais burguesas, porque estão acima da lei. O Brasil não tem direitos humanos liberais, porque seus donos estão acima da lei. Sejam os coronéis de ontem e hoje ou os empresários corruptores, não há qualquer subordinação razoavelmente efetiva do poder econômico ao poder político.

A segunda luta é a luta para que os direitos humanos não sejam os direitos de uma burguesia domesticada, liberal, normatizada, cuja legião de excluídos só têm direito de voto. Esta luta pela transformação dos direitos humanos em direitos humanos 
plenos e não burgueses, é, no fundo, a luta pela transformação de nossas estruturas sociais, econômicas, produtivas, politicas. Esta luta, dificil por força dos interesses econômicos que aqui falam alto, é, no entanto, a barreira maior a ser vencida.

Um povo criado no eito, na escravidão, como é o caso do povo brasileiro, não chegou a ver no Estado o seu defensor, não chegou a ver na lei sua proteção, tampouco no Direito seu cajado. Eles são inimigos do povo, porque são simplesmente armas dos exploradores nacionais contra o povo. Por isso a luta pelos direitos humanos formais é também uma luta por trazer nossa gente à civilidade, retirando-a do confinamento a este capitalismo exploratório de requintes de crueldade típicos dos senhores de escravo. Estamos ainda num capitalismo escravagista melhorado; os direitos humanos liberais nos farão adentrar no capitalismo assalariado, da exploração do proletário. Mesmo assim não há que se negar a luta pela emancipação de nosso povo desta escravidão que é a falta de lei e de direitos.

Mas tampouco esta é a luta definitiva. A aposta do atual governo do Brasil é a de que é bem possível que empresas multinacionais e organismos financistas exploratórios venham a dar a lei que nos falta, o que é grande erro de cálculo histórico, mas que bem demonstra que entrar para a civilização capitalista não exige o esforço maior do que o esforço de um mercado econômico liberal e de direito.

Por isso a luta pelos direitos humanos é sempre uma luta maior. Quando se nega a suficiência dos direitos humanos liberais, não se o faz para voltar ao passado. Cada época da dialética histórica fecha as comportas do passado. A crítica aos direitos humanos liberais não é a volta à servidão ou à escravidão, é a crítica prospectiva, é a crítica de aprofundamento, de superação, e não de retorno. Assim sendo, qualquer negação dos direitos humanos, qualquer violação, qualquer ditadura, devem ser rechaçados veementemente por conta de sua atrocidade. A crítica à insuficiência desta voga dos direitos humanos é a crítica à sua compreensão meramente formalista, individualista, à serviço dos grandes grupos multinacionais. Não representa a crítica feita a favor da truculência, é antes de tudo a crítica contra a truculência da tortura fisica e contra a truculência da miséria legalizada.

É por essa razão que, no mundo atual, no qual se desmobilizam os mínimos padrões de regulação social estatal, no qual volta a lei do mercado em nível mundializado, é preciso insistir nos direitos humanos, mas numa perspectiva maior. A tutela dos direitos humanos, individuais, sociais e de classe, é elemento de tensão e de permanência na batalha pela superação das explorações sociais. O Estado, que no século XX foi grandemente inimigo das transformações sociais, nesta entrada de século XXI, na qual o mercado mundializado desmantela o Direito e a Política em troca dos lucros fáceis, é ainda um bastião para que a luta pela transformação social seja uma luta plena, para o futuro melhor, e não apenas para estancar o retrocesso. Os direitos humanos formais, sociais principalmente, hoje estão sendo desmantelados em todo o mundo em troca dos interesses de mercado. A luta pelos direitos humanos, pela sua tutela jurídica, é a luta por estancar a barbárie mais crescente ainda. Nunca a tutela dos direitos humanos, vale dizer, nunca o Direito teve papel tão relevante no sentido de estancar a barbárie 
capitalista quanto nos últimos anos. Nisto concorda até o insuspeito Habermas, que funda no direito a possibilidade de sociabilidade ainda restante no capitalismo. ${ }^{\rtimes}$ Por isso a luta pelos direitos humanos e a tutela assegurada destes direitos dentro do Estado e do Direito é fundamental nos dias de hoje. A barbárie do capitalismo, na atualidade, é antiestatal, não é por dentro do Estado, mas é contra ele. Por isso ainda a instância estatal é a possibilidade de manter a luta pela plenificação da Justiça, dos direitos humanos e da transformação no patamar do capitalismo regulado para além dele, não deixando resvalar o problema para a luta contra a barbárie dos senhores feudais sem lei cujos feudos são hoje as empresas transnacionais e o narcotráfico que corrompe as estruturas legais.

O ilustre professor Dalmo de Abreu Dallari expressa com muita clareza esta luta ainda hoje presente na realidade jurídica brasileira:

"Em conclusão, pode-se dizer que a entrada do século XXI assiste no Brasil ao confronto de duas concepções de sociedade. Uma delas é a tradicional, que se apóia numa interpretação distorcida do liberalismo rotulada de neoliberalismo, apregoando o respeito à liberdade, como direito formal, mas atenta apenas ao mundo dos negócios, ao mercado, sem qualquer preocupação com a justiça social. (...)

Outra concepção, que vai ganhando novos adeptos e já se faz ouvida hoje, começando a pesar nas decisões politicas, é de caráter humanista. Para os adeptos dessa concepção de sociedade, a primeira prioridade é a pessoa humana, com sua dignidade e seus direitos fundamentais. O que permitiu o surgimento dessa concepção foi o aparecimento do povo como protagonista da história, como bem assinalou Florestan Fernandes. "')

A luta pelos direitos humanos é a luta pelo estancar da barbárie, pelo estancar do retrocesso, mas não deve ser só esta luta negativa, que se limita ao formalismo que também é capitalista e que também não revoluciona, no máximo é reformista. É preciso a luta positiva, pela afirmação não apenas formal, mas concreta, plena, social, do homem. Por isso, a luta pelos direitos humanos sempre foi a luta pela sociedade justa. Sua tutela formal é imprescindível aos nossos dias neoliberais, pois sedimenta o chão da batalha. A consciência da transformação social, no entanto, é a parede que se levanta deste chão forte, é o abrigo da sociedade plena e da Humanidade justa.

São Paulo, agosto de 2002.

8. HABERMAS, Jürgen. Direito e Democracia: entre validade e facticidade. 2" v. Rio de Janciro, Tempo Brasilciro, 1997. Nesta obra, Habermas inscreverá scu agir comunicativo, que garante a possibilidade de entendimento $\mathrm{e}$ de Justiça, portanto, em procedimentos c garantias juridicas.

9. DALLARI, Dalmo de Abrcu. "Socicdade, Estado c dircito: caminhada brasilcira rumo ao sćculo XXI" In Carlos Guilherme Mota (org.), Viagen Incompleta. A Experiencia Brasileira. A Grande Transação. São Paulo, Ed. Scnac, 2000, pp. 486 c 487. 